\begin{tabular}{|l|l|}
\hline Reflexión política y pasión humana en el realismo de Maquiavelo & Titulo \\
\hline Braun, Rafael - Autor/a & Autor(es) \\
\hline Fortuna y Virtud en al República Democrática. Ensayos sobre Maquiavelo & En: \\
\hline Buenos Aires & Lugar \\
\hline CLACSO, Consejo Latinoamericano de Ciencias Sociales & Editorial/Editor \\
\hline 2000 & Fecha \\
\hline & Colección \\
\hline politica; filosofia; teoria politica; filosofia politica; historia; & Temas \\
\hline Capítulo de Libro & Tipo de documento \\
\hline http://bibliotecavirtual.clacso.org.ar/clacso/se/20100603025521/5braun.pdf & URL \\
\hline $\begin{array}{l}\text { Reconocimiento-No comercial-Sin obras derivadas 2.0 Genérica } \\
\text { http://creativecommons.org/licenses/by-nc-nd/2.0/deed.es }\end{array}$ & Licencia \\
\hline
\end{tabular}

Segui buscando en la Red de Bibliotecas Virtuales de CLACSO

http://biblioteca.clacso.edu.ar

Consejo Latinoamericano de Ciencias Sociales (CLACSO)

Conselho Latino-americano de Ciências Sociais (CLACSO)

Latin American Council of Social Sciences (CLACSO)

www.clacso.edu.ar

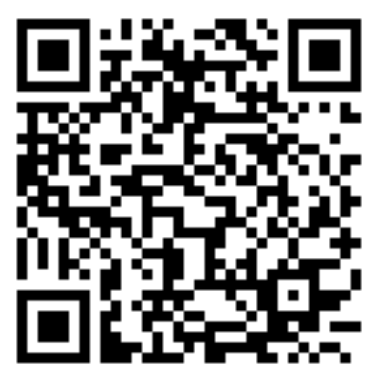


Braun, Rafael. Reflexión política y pasión humana en el realismo de Maquiavelo. En publicacion: Fortuna y Virtud en al República Democrática. Ensayos sobre Maquiavelo. Tomás Várnagy CLACSO, Consejo Latinoamericano de Ciencias Sociales, Ciudad Autónoma de Buenos Aires, Argentina. 2000. ISBN: 950-9231-54-1 Disponible en la web: http://bibliotecavirtual.clacso.org.ar/ar/libros/maquiavelo/braun.pdf

Fuente: Biblioteca Virtual de Ciencias Sociales de América Latina y el Caribe de la red CLACSO - http://www.clacso.org.ar/biblioteca

\section{Reflexión política y pasión humana en el realismo de M aquiavelo}

$\approx$ Rafael Braun*

$\mathrm{S}$ on muchos los autores que piensan que la ciencia política contemporánea se halla en un estado de crisis. Los síntomas de la misma son varios, pero entre ellos se destaca la falta de unanimidad que existe entre los científicos respecto del método más apropiado para aprehender toda la riqueza contenida en la realidad política. La polémica entablada entre las diversas posiciones da la impresión, de a ratos, de haber conducido el problema a una impasse, y uno termina por preguntarse si aún es posible decir algo verdadero acerca de la política que pueda ser compartido en cuanto tal por el que habla y por el que escucha, por quien escribe y por quien lee.

Cuando se llega a esta situación lo mejor es dar un paso atrás y retomar el problema desde otra perspectiva. Sobre política se viene escribiendo inteligentemente desde hace más de dos mil años, y recurrir a esta amplia tradición puede ser fecundo en las actuales circunstancias. En la historia del pensamiento político hay un autor que tiene el mérito de concitar permanentemente la atención tanto del filósofo como del científico y del político, porque ha hablado en una forma que nadie ha podido igualar desde entonces. Me refiero, claro está, a Maquiavelo. Sus opiniones merecen los juicios más encontrados y despiertan sentimientos contradictorios, pero quien quiera hablar hoy de política no puede ignorarlo.

Mi propósito en este trabajo es analizar el alcance del "realismo" maquiavélico y los presupuestos antropológicos que sirven de fundamento a sus célebres máximas.

"Doctor en Filosofía (Lovaina), Licenciado en Teología (UCA), Profesor de Teoría Moral en la Facultad de Teología de la Universidad Católica Argentina. 
No es mi intención desarrollar el tema desde la perspectiva de una historia de las ideas, sino rescatar aquellos elementos del pensamiento de Maquiavelo que, por su universalidad, nos permiten entablar con él un diálogo de rigurosa actualidad.

\section{El realismo de Maquiavelo}

La interpretación correcta de un autor exige el conocimiento del propósito que lo guía al escribir. Por ello creo útil partir del célebre pasaje del capítulo XV de El Príncipe, donde se encuentra claramente explicitada la intención que anima a Maquiavelo:

"Conviene ahora ver cómo debe conducirse un príncipe con sus súbditos o con sus amigos. (...) Siendo mi intención escribir cosas útiles para quien las comprenda, me ha parecido más conveniente ir directamente a la verdad efectiva (veritá effetuale) de las cosas que a la imaginación de las mismas. Muchos han imaginado repúblicas y principados que jamás fueron vistos ni conocidos como verdaderos porque hay tanta distancia de la manera en que se vive a la forma en que se debiera vivir, que aquel que deja aquello que se hace por aquello que debería hacerse prepara más bien su ruina que su preservación. Porque un hombre que se empeña en ser siempre bueno no puede evitar su perdición entre tantos que no lo son. De allí que sea necesario al príncipe que quiera sostenerse aprender a poder dejar de ser bueno, para serlo o no serlo según la necesidad lo requiera" (El Príncipe: cap. 15).

Este texto está estructurado en torno a dos oposiciones. La primera contrapone la percepción de la verdad efectiva de las cosas a lo que sólo existe en la imaginación, con el objeto de afirmar la preeminencia de lo que existe en la realidad. De la consideración de esta realidad surge la segunda oposición entre lo que los hombres hacen y lo que deberían hacer, distinción situada en el plano del comportamiento o del obrar humano. Cuando uno imagina repúblicas o principados la tentación es frecuente por construir el edificio político sobre la base de que los hombres son buenos y razonables, sin advertir que esta generalización también es producto de la imaginación. Lo que se constata en la realidad, en cambio, es la oposición y lucha entre el hombre de bien y el que no lo es, y un divorcio entre lo que los hombres hacen y dicen que hay que hacer. Cabe entonces distinguir no sólo entre cómo son y cómo deberían ser las repúblicas y principados, sino también entre cómo son los hombres y cómo deberían ser desde el punto de vista ético.

Estas distinciones de Maquiavelo están encuadradas en un contexto prescriptivo, ya que la opción en favor del realismo gnoseológico está en función de un realismo de la conducta a su vez puesto al servicio de un fin político. Se trata de prescribir al príncipe -y, por extensión, a todo hombre político- cómo debe actuar si quiere preservar o acrecentar su poder, y no de establecer una perfecta censura lógica entre el ser y el deber ser en busca de una perfecta objetividad. 
Esta diferencia de perspectiva se ve con más claridad si se compara la posición de Maquiavelo con la de Aristóteles. Refiriéndose al criterio que permite definir quiénes son ciudadanos en una comunidad política, éste introduce la distinción entre ser y deber ser, pero en un contexto descriptivo'. Lo que Aristóteles señala es que el "deber ser" postulado por el observador no altera la sustancia de la realidad, y por ello puede afirmarse que la distinción que establece se sitúa exclusivamente en el plano gnoseológico. Maquiavelo quiere operar sobre la realidad, para lo cual debe conocerla. Aristóteles quiere, en cambio, describir la realidad. Aunque las distinciones sean similares responden a preocupaciones diferentes. Sería un error no tener siempre presente, en Maquiavelo, la intención pragmática que guía sus reflexiones.

Desechada la vía de la imaginación y descartado el recurso entonces habitual de proponer al príncipe un amplio catálogo de virtudes morales, Maquiavelo se propone investigar la verdad efectiva de las cosas políticas consultando los datos que le proporcionan dos fuentes: la propia experiencia y la lectura correcta de la historia. En la dedicatoria de El Príncipe afirma: “... nada he encontrado que ame y estime tanto como el conocimiento de las acciones de los grandes hombres, que he aprendido por una larga experiencia de las cosas modernas y una continua lectura de las antiguas: sobre lo cual he pensado y reflexionado largamente y con gran cuidado...", idea retomada casi en los mismos términos en la dedicatoria de los Discursos ${ }^{2}$.

La participación de Maquiavelo en los asuntos públicos de Florencia comienza el 19 de junio de 1498 cuando es electo secretario de la segunda Cancillería. Durante los catorce años en que permaneció en la función pública tuvo ocasión, como diplomático, de entrar en contacto y ver actuar de cerca a importantes personajes de su tiempo. En tres ocasiones -en 1500, 1504 y 1510- es enviado a Francia a la corte de Luis XII. En 1502-3 sigue de cerca las maquinaciones y campañas de César Borgia. Está en Roma cuando es electo Papa Julio II en 1503, ciudad a la que retorna en 1506. En 1508 es enviado a la corte del emperador Maximiliano, donde efectúa una estadía de cinco meses. Desde 1505 hasta su deposición el 7 de noviembre de 1512 juega un papel importante en la creación, organización y dirección de la milicia florentina. Su experiencia política se completa en 1513 cuando es detenido y torturado por presunta complicidad en un complot contra los Médici.

Los informes diplomáticos enviados a la Señoría y las cartas dirigidas a sus amigos durante este período contienen en germen muchas de las observaciones y reflexiones que Maquiavelo sistematizará más tarde en sus obras. Lo que importa poner de relieve es que la reflexión política de Maquiavelo nace del contacto con la realidad, una realidad de la cual no sólo es testigo sino en la cual también es actor.

En el prefacio al Libro II de los Discursos, Maquiavelo compara el conocimiento que tenemos del pasado y del presente. Dice al respecto que "nunca se conoce toda la verdad sobre el pasado", porque se silencian algunos hechos y se am- 
plifican otros, y porque “... los hombres odian por miedo o por envidia, dos motivaciones que mueren con los hechos del pasado, los cuales no pueden inspirar ni lo uno ni lo otro. Pero no sucede así con los acontecimientos en que somos actores, que ocurren bajo nuestros ojos: el conocimiento que de ellos tenemos es completo...". La contemporaneidad nos permite observar todos los hechos, pero además, al hacer posible nuestra participación en los mismos, permite que se despierten en nosotros las mismas pasiones que animan al resto de los hombres. Para Maquiavelo el despertar de las pasiones es un elemento que coadyuva a un conocimiento más completo de la realidad, porque sólo así se está en medida de comprender el significado de las acciones políticas protagonizadas por hombres apasionados. Ser actor político no sólo ofrece un puesto de observación privilegiado a quien quiere conocer los secretos de la política sino que transforma al hombre privado en un "animal político", cuya experiencia vital podrá luego ser tematizada por la reflexión. El "realismo" de Maquiavelo no consiste en adoptar una posición desinteresada o "científica" ante la realidad; consiste en vivir dicha realidad y reflexionar sobre esa experiencia.

La segunda fuente a partir de la cual puede conocerse la "verdad efectiva" de las cosas es la historia. Maquiavelo alega que los hombres de su tiempo no se inspiran en los ejemplos del pasado porque carecen de un verdadero conocimiento de la historia. La mayoría de los que la leen se detienen únicamente en el placer que les causa la variedad de acontecimientos que presenta, sin advertir que un estudio más profundo permite captar la existencia de un orden permanente en el universo.

La conclusión principal que se desprende para Maquiavelo de la lectura de la historia es que "... quienquiera compare el presente al pasado ve que todas las ciudades, todos los pueblos siempre han estado y están aún animados de los mismos deseos y los mismos humores..." (Discursos: Libro I, cap. 39). Si el conocimiento de los hechos del pasado nos revelara solamente una serie de acontecimientos inconexos y heterogéneos, el saber histórico sería de poca utilidad para el hombre del presente. La intención pragmática que anima a Maquiavelo lo impulsa a descubrir las similitudes en las situaciones más diversas, y cree encontrar en las características básicas de la condición humana el elemento estable y permanente que confiere inteligibilidad a los procesos históricos.

De esta conclusión se desprenden dos consecuencias de peso. La primera es que las acciones de los grandes hombres pueden ser imitadas no obstante la diversidad de las circunstancias. Sus figuras se constituyen así en prototipos que ilustran las diferentes posibilidades abiertas al hombre, y por eso son dignas de estudio. Sus éxitos y sus fracasos son "lecciones" ofrecidas a quien está dispuesto a desentrañar el significado no anecdótico de los acontecimientos.

La segunda consecuencia es que “... es fácil, para quien examina con diligencia las cosas del pasado, prever lo que ocurrirá en una república, y entonces usar los medios empleados por los antiguos o (...) imaginar nuevos según la similitud 
de los acontecimientos...", estudios rara vez emprendidos y siempre ignorados por los que gobiernan, por lo cual siempre vuelven los mismos males (Maquiavelo, Discursos: Libro I, cap. 39). “... Los hombres prudentes suelen decir con razón, que para prever el futuro hay que consultar el pasado, pues los acontecimientos del presente encuentran siempre en ese pasado su correspondencia. Realizados por hombres que están y que siempre han estado animados de las mismas pasiones, deben éstas necesariamente producir los mismos efectos..." (Maquiavelo, Discursos: Libro III, cap. 43). El conocimiento de la historia, obtenido a través de una lectura efectuada a la luz de la conclusión empírica de la inmutabilidad de la naturaleza humana, coloca al estudioso en inmejorable posición para operar con éxito sobre la realidad. Maquiavelo se muestra aquí también más interesado en obtener conocimientos "útiles" para actuar en política que en alcanzar un conocimiento exhaustivo de los hechos que quizás pudiera obtenerse asumiendo la actitud desinteresada del científico profesional. En lenguaje contemporáneo diría que sólo le interesan las variables relevantes directamente manipulables por el político.

\section{La antropología de Maquiavelo}

Un estudio de las obras de Maquiavelo revela que estas variables relevantes son para él los deseos y pasiones permanentes de los hombres. La importancia que les acuerda en su análisis induce, incluso, a algunos a reducir su "realismo" a una

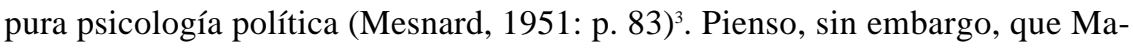
quiavelo no se detiene en una mera descripción del comportamiento efectivo de los hombres sino que formula una teoría del hombre que pretende dar cuenta, en el plano filosófico, de los fenómenos observados. Esta teoría, como se sabe, da una visión pesimista de la condición humana que se manifiesta, a mi juicio, en dos planos, vinculados entre sí en el análisis de Maquiavelo, pero que cabe distinguir a fin de poder valorar separadamente proposiciones no dependientes entre sí.

El primer tipo de pesimismo, de carácter ontológico, se funda en el hecho de que "... los deseos de los hombres son insaciables; porque la naturaleza le da poder y querer desear todo, pero la fortuna le da el poder conseguir poco. De allí resulta en él un descontento habitual y el disgusto por lo que posee; es lo que hace acusar al presente, alabar al pasado, desear el futuro, y todo ello sin ningún motivo razonable..." (Maquiavelo, Discursos: Libro II, prefacio).

El hombre es concebido como un sujeto de deseos y pasiones y no como un ser razonable dispuesto a reconocer y a aceptar los límites de su propia finitud. Es un perpetuo insatisfecho porque hay una desproporción esencial entre sus aspiraciones y las posibilidades de satisfacerlas.

Partiendo del principio de que “... todos los hombres (...) nacen, viven y mueren siempre según un mismo orden...” (Maquiavelo, Discursos: Libro I, cap. 11), descubre en la insaciabilidad del deseo el fundamento de la ambición, y en ésta 
la causa inextinguible de la lucha entre los hombres. “... Todas las veces que los hombres están privados de combatir por necesidad, combaten por ambición. Esta pasión es tan poderosa que no los abandona jamás, cualquiera que sea el rango que ocupan..." (Maquiavelo, Discursos: Libro I, cap. 37).

Esta concepción del hombre contrasta radicalmente con el ideal del hombre virtuoso propuesto por Aristóteles, porque para Maquiavelo "... no es dado a nuestra naturaleza poder situarse exactamente en una vía media..." (Discursos: Libro III, cap. 21). En esta afirmación subyace la idea de que la grandeza del hombre no consiste en equilibrar entre sí a las pasiones opuestas, hasta anularlas, por medio de la razón, sino en seguir hasta el extremo la lógica propia de las pasiones.

Esta lógica es la que nos hace comprender por qué el dinamismo de la ambición humana no encuentra nunca reposo, sean cuales fueren las circunstancias políticas y económicas en que se hallen los hombres. El motor de la lucha y el conflicto anida en el corazón del hombre, no en las contradicciones de la sociedad, y como él permanece idéntico a sí mismo a través de la historia, la creencia en el progreso de la humanidad es más un producto de la imaginación que el fruto de la consideración de la "verdad efectiva" de las cosas. La filosofía cíclica de la historia que retoma de Polibio es la expresión coherente de esta visión del hombre.

La primera forma de pesimismo, pues, está referida a rasgos constitutivos, estructurales, de los hombres. Estos no gobiernan su vida con la razón, sino por las pasiones, las cuales se alimentan de deseos insaciables generadores de conflictos y por lo tanto de un permanente desasosiego ${ }^{4}$.

El segundo plano en que se manifiesta el pesimismo de Maquiavelo es el de la ética. La creencia de que “... los hombres están más inclinados al mal que al bien...” (Discursos: Libro I, cap. 9) atraviesa toda su obra y colorea sus máximas más famosas, provocando la reacción airada de los "humanistas" de todos los tiempos.

Maquiavelo no sólo no se hace ilusiones respecto a la disposición habitual de los hombres a obrar bien, es decir a que prevalezcan las buenas pasiones sobre las malas, sino que piensa que "... los hombres no hacen el bien más que forzados; pues apenas tienen la posibilidad y la libertad de cometer el mal impunemente, no dejan de provocar en todas partes el tumulto y el desorden..." (Discursos: Libro I, cap. 3). Liberado a su espontaneidad el hombre tiende a cometer el mal, y al respecto cabe recordar que para Maquiavelo si los hombres se unen entre sí para formar una comunidad política lo hacen impulsados por la necesidad de defenderse de la agresión ajena. Es asimismo significativo que en la explicación que da del origen de las diferentes formas de gobierno, atribuya a la existencia del gobierno el conocimiento de lo bueno y lo malo, y de la justicia (Maquiavelo, Dis cursos: Libro I, cap. 2)5. Es decir que el estado de sociedad política, lejos de corromper la bondad natural del hombre, está destinado a contener la inclinación natural del hombre a dañar a su semejante. 
El pesimismo ético de Maquiavelo va a encontrar su fórmula más tajante en este célebre pasaje de los Discursos: “... Como demuestran todos aquellos que se han ocupado de política (y la historia está llena de ejemplos que lo apoyan) es necesario que quien quiera fundar una república y darle leyes, presuponga de antemano malos a los hombres y siempre listos a mostrar su maldad cada vez que se les presenta una ocasión. Si esta inclinación permanece oculta por un tiempo, hay que atribuirlo a alguna razón que uno no conoce, y creer que no ha tenido ocasión de manifestarse; pero el tiempo que, como se dice, es el padre de toda verdad, la pone luego en evidencia...” (Maquiavelo, Discursos: Libro I, cap. 3).

La inclinación hacia el mal que Maquiavelo descubre en el hombre es una tendencia profunda y permanente comparable a la concupiscencia desordenada que la doctrina cristiana atribuye al pecado original. Pero mientras el cristianismo proclama como núcleo de su mensaje la redención del hombre por obra de Cristo y la posibilidad de vencer el mal con la ayuda divina, Maquiavelo, situado en el plano político y no en el religioso, piensa que esta inclinación al mal no puede ser erradicada y que sólo puede, y debe, ser contrarrestada por la autoridad pública no dándole ocasión para que se manifieste.

La intención pragmática asoma aquí nuevamente al prescribir Maquiavelo una conducta a quien quiera dedicarse a la política. No se puede entrar al ruedo suponiendo ingenuamente que los hombres son razonables y buenos. El único modo de cubrirse de sorpresas desagradables es partir del supuesto contrario. Con esta suposición no se descarta que puedan existir hombres que viven según la razón procurando obrar el bien, pero sí se descarta que puedan servir de paradigma del ciudadano en la construcción de un orden político, porque son la excepción y no la regla. El conocimiento de la verdadera naturaleza del hombre, lejos de ser un pasatiempo de filósofos, se transforma así en el requisito indispensable para obrar con éxito en el campo político. El pesimismo antropológico de Maquiavelo no se complace en una descripción de las debilidades humanas ante las cuales el hombre se muestra impotente; es un pesimismo pragmático que permite discernir con claridad la fantasía de la realidad a fin de que el hombre de acción, liberado de falsos escrúpulos e ilusiones, pueda afrontar en condiciones ventajosas la lucha por el dominio de esa realidad.

\section{El breviario del hombre público}

Una vez liberado de las ilusiones sostenidas con respecto a los demás hombres, Maquiavelo se dispone a liberar al político de los escrúpulos de conciencia originados en principios éticos. Para ello va a profundizar una distinción ya insinuada por Aristóteles cuando afirma que no es lo mismo ser un buen hombre que un buen ciudadano (1951: Libro III, cap. 4).

El político es un hombre que vive en función de la búsqueda y el mantenimiento del mando público. Desarrolla su actividad en una esfera que, según Ma- 
quiavelo, tiene sus propias reglas y por ello mismo sus propios principios éticos. Existe una moral propia al hombre privado y otra que corresponde al hombre público. Todo intento de desconocer esta distinción fundamental de planos conduce irremediablemente a la irresolución o al moralismo, dos "soluciones" que no hacen más que agravar los males que se pretenden evitar, porque representan compromisos bastardos entre principios imposibles de conciliar en la práctica ${ }^{6}$.

Afirmada la autonomía de la acción política, Maquiavelo establece ciertos principios generales destinados a servir de guía a los hombres que se aventuran en la esfera de lo público.

“... En todas las acciones de los hombres (...) se encuentra siempre junto al bien algún mal tan íntimamente ligado con él que es imposible evitar lo uno si se quiere lo otro..." (Maquiavelo, Discursos: Libro III, cap. 37). Este principio equivale a afirmar que en política no hay acciones puras, absolutamente buenas o absolutamente malas; que el mal y el bien se mezclan como el trigo y la cizaña de la parábola, y que toda aproximación maniquea debe ser desechada en este ámbito por no respetar la ambigüedad intrínseca que lo caracteriza.

Una consecuencia del principio anterior es la relación especial que liga a los medios empleados por un actor político con el fin que persigue. Maquiavelo se muestra aquí enteramente franco al aceptar sin reservas que el fin justifica a los medios. “... Un espíritu sabio nunca condenará a alguien por haber usado un medio fuera de las reglas ordinarias para reformar una monarquía o fundar una república. Lo que es de desear es que si el hecho lo acusa, el resultado lo excuse; si el resultado es bueno es absuelto. (...) No es la violencia que restaura, sino la violencia que arruina la que hay que condenar..." (Maquiavelo, Discursos: Libro I, cap. 9). Lo que esta formulación expresa es que una acción política no puede ser juzgada abstractamente cotejándola con un principio de validez universal, porque no se aprehendería de este modo el significado que posee. La calificación moral de un acto requiere no sólo conocer su objeto sino también las circunstancias en que se desenvuelve y la intención que lo preside. Requiere por lo tanto dilucidar el significado que adquiere dicho acto en cuanto se halla inscripto en un orden concreto de fines y medios.

En esta perspectiva el problema de la justificación de los medios se emparenta con el de la jerarquía que establece un sujeto en el conjunto de valores a que adhiere. El siguiente pasaje es ilustrativo al respecto: “... si se trata de deliberar sobre la salvación [de la patria], [el ciudadano obligado a dar consejo] no debe ser detenido por ninguna consideración de justicia o de injusticia, de humanidad o de crueldad, de ignominia o de gloria. El punto esencial que debe imponerse sobre todos los demás es asegurar su salvación y libertad..." (Maquiavelo, Discur sos: Libro III, cap. 41). Como afirma en síntesis el título de dicho capítulo, "La patria debe defenderse con ignominia o con gloria; de cualquier modo está bien defendida". Colocado el hombre en la obligación de obrar se ve muchas veces en- 
frentado a disyuntivas que le exigen optar por alguno de los caminos que se le ofrecen a su elección. Esta opción se efectúa en función de la subordinación de ciertos valores a otros, pero elegida una vía se aplica el principio de que quien quiere el fin debe querer los medios para alcanzarlo, con lo cual los medios quedan justificados en relación al fin. Es claro que en el orden político esta justificación no es de orden moral; se encuentra más bien en el orden de la eficacia, de lo oportuno y conveniente. Un medio será considerado políticamente bueno si alcanza el fin político al que está ordenado. La relación fines y medios supone pues una jerarquía de valores, implícita o explícita, en el hombre público, en cuya cúspide éste coloca los bienes propiamente políticos como la seguridad externa e interna, la concordia y la prosperidad.

Lo que Maquiavelo quiere decir es que el político que juzgue a los medios no en relación a estos fines sino a los principios generales de la ética, no es un buen político y mejor sería que se retirara a la vida privada, porque sería como un soldado que en plena guerra no se decide a matar al enemigo por motivos de conciencia ${ }^{7}$. La justificación de los medios por el fin puede interpretarse, pues, de dos maneras. O bien como la desvinculación del orden político con respecto al orden moral, o bien como la reafirmación de la lógica propia del orden político. Pienso que esto último es lo que persigue Maquiavelo, y quienes lo acusan de inmoralista deben mostrarse capaces de afrontar el problema que plantea y darle una respuesta que tenga valor operativo para el hombre público. Porque si bien debe reconocerse que toda acción tiene una dimensión moral, la acción política se halla enmarcada en circunstancias tan peculiares que su moralidad no puede ser determinada con los mismos criterios que se utilizan para calificar las acciones privadas de los hombres.

El dilema presente en toda jerarquización de valores repercute a su modo en la obligación en que se encuentra el hombre público de escoger entre todas las virtudes aquellas más deseables para el ejercicio de su función, pues esta elección la realiza en base a los valores supremos que postula en el orden político. “... Sé que todos convendrán en que sería muy loable que un príncipe tuviera de las antedichas cualidades sólo las que son buenas; pero, como no se pueden tener todas, ni ponerlas enteramente en práctica, porque la condición humana no lo permite, debe ser suficientemente prudente para evitar la infamia de los vicios que le harían perder sus estados, y para preservarse de los demás, si es posible. (...) No tema incurrir en infamia por aquellos vicios sin los cuales no puede conservar sus estados, porque considerándolo bien, tal cosa que parezca virtud podría perderle si la practicase; y otra que parezca vicio puede ser la causa de su seguridad y su bienestar..." (Maquiavelo, El Príncipe: cap. 15).

Este pasaje contiene dos afirmaciones que conviene distinguir. La primera se refiere a la imposibilidad práctica, dada nuestra condición humana, de acumular todas las virtudes deseables, imposibilidad que sirve de fundamento a la opción 
que debe realizar el hombre entre las diversas maneras de ser virtuoso que se le proponen. La vocación del monje contemplativo requiere el desarrollo de aquellas virtudes apropiadas a su estado, y que por cierto difieren de las que se adecuan a la condición de comerciante o las necesarias al político. La clásica caracterización que hizo Max Weber de las diferentes vocaciones del científico y del político pone precisamente de relieve este punto al señalar que cada vocación tiene su deontología particular. Al no existir un modo genérico de ser virtuoso, el hombre debe escoger el modo específico de ser virtuoso que corresponda a su vocación. La primera recomendación de Maquiavelo consiste en decirle al político que debe proceder según este criterio.

La segunda afirmación se refiere a los recursos que debe utilizar el príncipe para preservar sus intereses mediante la conservación del poder. Es inevitable señalar aquí que para Maquiavelo el interés particular del príncipe se opone generalmente al bien público del estado, trayendo como consecuencia el debilitamiento del mismo ${ }^{8}$, por lo cual sus recomendaciones no deben ser interpretadas como si el conservarse en el poder fuera para él el valor supremo. Conviene en todo caso advertir que la conducta egoísta del príncipe es juzgada negativamente no porque contraviene a normas éticas sino porque es un obstáculo a la grandeza del estado.

Dado el carácter malvado de la mayoría de los hombres, hay que estar dispuesto a incursionar en el mal si uno quiere seguir siendo hombre público. Esta recomendación es el meollo del capítulo XVIII de El Príncipe, en el que Maquiavelo justifica que no se cumplan las promesas y los pactos apoyándose en el hecho de que los demás, por ser malvados, tampoco respetarán la palabra empeñada?.

La distinción tajante entre el bien y el mal demuestra a las claras que Maquiavelo reconoce la existencia de un orden ético con vigencia independiente de la voluntad del poder público. La conducta del político es calificada por las normas morales, lo cual significa que debe enfrentar, como todo hombre, la disyuntiva de obrar conforme a la norma o alejándose de ella. El problema reside en que el horizonte del político siempre hay una meta que condiciona todos sus actos: la conquista o el mantenimiento del poder, una condición que Maquiavelo se apresura a reconocer. “... Si el príncipe quiere conservar sus estados, está obligado a menudo a no ser bueno...” (Maquiavelo, El Príncipe: cap. 19). “... Un príncipe, sobre todo cuando es nuevo (...) está a menudo obligado, para mantener sus estados, a obrar contra su palabra, contra la caridad, contra la humanidad, contra la religión. Es por ello que debe (...) no alejarse del bien, si puede, pero saber entrar en el mal si es necesario..." (Maquiavelo, El Príncipe: cap. 18).

En la decisión del político de recurrir a procedimientos reñidos con la ética, la libertad humana está dos veces comprometida; la primera al escoger la propia vocación y, la segunda, al decidir querer ser un político de éxito y no un fracasado. Esto no significa, como piensa el maquiavelismo fácil, que en la arena política todo está permitido, cualesquiera sean las circunstancias. Para Maquiavelo 
"entrar en el mal" es el recurso extremo al que se apela luego de agotado el camino del bien y en caso de que sea necesario para el éxito de la empresa propuesta. Querer tener éxito depende exclusivamente de uno mismo, pero la necesidad inscripta en ciertas situaciones creadas por la maldad de los hombres escapa a nuestro control. Es un dato que hay que tomar en cuenta si se quiere operar con eficacia sobre la realidad. Por ello la recomendación de Maquiavelo debe interpretarse como un corolario de su pesimismo ético.

\section{Fortuna, necesidad y conflicto}

Estos consejos dirigidos al hombre que quiere hacer política están en último término fundados en ciertas leyes constitutivas de la condición humana histórica, concreta. Lo que ellas revelan es la finitud y la limitación del hombre, y la ambigüedad radical de su situación en el mundo. Tomar conciencia de los propios límites es para Maquiavelo el comienzo de la sabiduría, y por eso se empeñará en mostrar cuáles son.

“... El orden de las cosas humanas es tal que nunca se puede huir de un inconveniente sin caer en otro. Sin embargo la prudencia consiste en saber conocer la calidad de esos inconvenientes y elegir el menor como bueno..." (Maquiavelo, El Príncipe: cap. 21) ${ }^{10}$. Para Maquiavelo el hombre en situación tiene que elegir, entre los cursos de acción posibles, el que menos inconvenientes le acarree, pues creer que existe una solución perfecta que consulte todas las aspiraciones y alcance todos los objetivos es una mera ilusión. Sensible sobre todo al aspecto negativo que inevitablemente arrastran consigo las realizaciones humanas, erige el principio de elegir el mal menor como norma suprema de la prudencia. Hombre prudente es aquel que, por conocer la verdadera naturaleza de las cosas, está en condiciones de prever las consecuencias que se seguirán de determinadas decisiones. El hombre prudente sabe que existe una enorme distancia entre el proyecto y el resultado, entre la intención y el efecto, y por ello organiza modestamente el dinamismo de su conciencia en función del mal que desea evitar. Porque este método, al permitirle circunscribir el mal irreductible, le está señalando al mismo tiempo el mayor bien posible de alcanzar.

La limitación del hombre no sólo se refleja en el plano ético sino que alcanza a su misma libertad. ¿En qué medida puede el hombre dominar los acontecimientos históricos? ¿En qué medida es dueño de su destino? Maquiavelo confiesa en El Príncipe que él compartió alguna vez la idea de que la fortuna gobierna de tal modo las cosas del mundo que a los hombres no les es dable, con su prudencia, dominar lo que tienen de adverso esas cosas. Sin embargo, atento a que ello implicaría negar enteramente el libre albedrío del hombre y, por ende, toda posibilidad de modificar conscientemente el curso de la historia, declara que las acciones de los hombres están gobernadas, en parte, por la fortuna y, en parte, por ellos mismos (Maquiavelo, El Príncipe: cap. 25). 
Esta distribución salomónica de esferas de influencia no significa que ambas áreas estén perfectamente delimitadas y que tanto la fortuna como la libertad ejerzan sus respectivos dominios en la mutua prescindencia. Para Maquiavelo entre fortuna y libertad se establece una dialéctica de oposición y lucha cuya premisa básica es que ambos polos son realidades irreductibles. El hombre puede ampliar la esfera de la libertad en la medida en que, asumiendo su condición de ser libre e inteligente, no se deja abatir por la certeza de saber que hay en su existencia un dominio propio de la fortuna constituido por todo aquello que escapa a su gobierno y previsión. En la medida en que cede al fatalismo abdica de su libertad y se entrega inerme en manos de la fortuna; por el contrario, en cuanto desentraña la verdadera naturaleza de las realidades políticas toma conciencia de sus posibilidades de acción así como de los límites que la acotan. En ocasiones Maquiavelo pone de relieve la disposición activa del hombre, capaz de doblegar mediante una acción audaz el dominio de la fortuna ${ }^{11}$. En otro lugar insiste más bien en el carácter limitativo de la fortuna, que obliga al hombre a adaptarse a las circunstancias que ella crea. Ello no implica que en la posición de Maquiavelo haya pasividad o resignación, sino una lúcida conciencia de que la libertad del hombre está situada en un mundo ya dado que él no puede cambiar a su antojo ${ }^{12}$.

El tema de la necesidad se inserta naturalmente en este marco para acotar aún más la acción del hombre. En efecto, “... la necesidad dirige a menudo hacia un fin al que la razón estaba lejos de conducir...” (Maquiavelo, Discursos: Libro I, cap. 6). Es verdad que el hombre nunca hubiera alcanzado la perfección a que ha llegado si no hubiera estado impulsado por la necesidad ${ }^{13}$, pero no es menos cierto que el estado de necesidad coloca al hombre en situaciones en donde las posibilidades de elección son extremadamente limitadas.

Quizás ningún texto resuma mejor los diversos elementos que hemos venido analizando que la arenga que Maquiavelo pone en boca de un líder popular en el capítulo 13 del Libro III de las Historia de Florencia, que creo útil transcribir en su integridad para que se perciba mejor la fuerza de la argumentación.

"Si debiéramos decidir ahora si hay que tomar o no las armas, quemar y saquear las casas de los ciudadanos, robar las iglesias, yo sería de aquellos que juzgarían sensato reflexionar dos veces, y quizás aprobaría a aquellos que prefieren una miseria tranquila a ganancias peligrosas. Pero dado que se han tomado las armas y cometido muchos desmanes, creo que la única cosa a considerar es si no debemos guardarlas, y cómo podemos escapar a las consecuencias de los desmanes cometidos. Estoy convencido de que es la necesidad la que nos aconseja hacerlo. Ustedes lo ven: la ciudad entera resuena de quejas llenas de odio contra nosotros, los ciudadanos se agrupan, la Señoría se pone siempre del lado de los magistrados. Pueden estar seguros de que se trenza la cuerda para nosotros, de que se hacen nuevos preparativos contra nuestras cabezas. Nosotros debemos, por lo tanto, buscar dos cosas, y tener dos fines pre- 
sentes en nuestra deliberación: uno, escapar al castigo de nuestros desmanes de los últimos días; el otro, asegurarnos para el futuro una existencia más libre y más satisfactoria que la del pasado. Conviene pues, a mi juicio, si queremos que se nos perdonen los viejos pecados, cometer nuevos, redoblando los crímenes y multiplicando incendios y depredaciones. Debemos asegurarnos el mayor número posible de cómplices, pues allí donde son muchos los que cometen el mal, nadie es castigado; pues son las faltas pequeñas las que se castigan; los grandes crímenes son recompensados. $\mathrm{Y}$ cuando muchos padecen pocos buscan vengarse, pues el daño que se hace a todos se soporta con más paciencia que el que le es infligido a uno. Por consiguiente, multiplicar los crímenes nos obtendrá más fácilmente el perdón y, además, los medios para obtener lo que deseamos para ser libres. Y creo que caminamos a un éxito seguro, pues aquellos que nos lo disputan son ricos y están divididos: sus divisiones nos darán la victoria, y sus riquezas, cuando sean nuestras, nos la conservarán. Y no dejéis que os refrieguen en la cara la antigua nobleza de su sangre, porque todos los hombres, habiendo tenido un mismo principio, son igualmente antiguos, y han sido hechos por la naturaleza del mismo modo. Pongámonos todos desnudos: nos veréis a todos iguales. Pongámonos sus ropas y ellos las nuestras: sin duda seremos nosotros los que tendremos aire de nobles y ellos de miserables. Porque sólo la pobreza y la riqueza nos desigualan".

"Lo que me duele mucho es enterarme que hay entre vosotros algunos que, por conciencia, se arrepienten de los hechos cometidos, y quieren abstenerse de cometer nuevos; en cuyo caso, si es verdad, no sois los hombres que yo creía que erais. ¿En qué esos términos de conciencia, de infamia, pueden asustaros? Porque los que vencen, de cualquier modo que venzan, nunca cosechan vergüenza; y no debemos tener en cuenta a la conciencia, pues en personas como nosotras, llenas de miedo -miedo del hambre, miedo de la prisión- no puede haber y no debe haber lugar para el miedo del infierno. Pero si miráis como proceden los hombres veréis que todos aquellos que adquieren gran riqueza y poder, han llegado a esa posición por el fraude y por la fuerza; luego, una vez que los han así usurpado por fraude y por violencia, los decoran con el nombre de ganancia justa. Los otros, aquellos que por ineptitud o su extrema estupidez, no obran como ellos, languidecen para siempre en la servidumbre y la miseria: pues los servidores fieles siempre son servidores, y los hombres buenos siempre son pobres. Sólo escapan a la servidumbre los infieles y audaces; sólo escapan a la pobreza los rapaces y los fraudulentos. Dios, la naturaleza, han colocado esos bienes al alcance de aquellas personas, más accesibles a la rapiña y a las maniobras fraudulentas que a una industria honesta. He aquí por qué los hombres se devoran entre sí, y por qué siempre el más débil es comido. Hay que emplear pues la fuerza cuando la ocasión se presenta, y la fortuna no puede presentarnos una mejor: los ciudadanos divididos, la Señoría que hesita, los magistrados asustados, y 
esto al punto que es fácil oprimirlos antes de que reaccionen y se agrupen; luego de lo cual seremos señores de la ciudad, sea totalmente, sea en gran parte para poder, no sólo ser perdonados de nuestros pasados excesos, sino amenazar a nuestros conciudadanos con nuevos atropellos. Confieso que este partido es audaz y peligroso, pero cuando la necesidad urge, la audacia es juzgada prudencia y en las circunstancias graves los hombres de valor nunca se han preocupado del peligro. Las empresas comenzadas con peligro terminan siempre con una recompensa, y no es sino por el peligro que se escapa del peligro. Creo sin embargo que cuando se preparan las cárceles, la tortura y la muerte, es más peligroso permanecer quieto que tratar de ir hasta el fin. En el primer caso está asegurada una conclusión fatal; en el segundo es dudosa. Os he escuchado a menudo denunciar la avaricia de vuestros superiores y la injusticia de vuestros magistrados. Ha llegado la hora, no sólo de que os liberéis de aquellas personas, sino de dominarlas, y que les toque a ellos el turno de temerles más a vosotros que vosotros a ellos. La oportunidad que presenta esta ocasión se escapa, y vano sería tratar de recapturarla una vez que se ha escapado. Veis que vuestros adversarios se preparan; anticipemos sus designios. Aquel de los dos que primero retome las armas será vencedor, su enemigo será abatido y él exaltado; habrá honor para muchos de entre nosotros, y para todos la seguridad".

El pasaje refleja con más intensidad que en las obras anteriores el pesimismo del autor, y constituye una suerte de prototipo del modo en que razona un hombre acosado por la necesidad aplicando los principios maquiavélicos. El resultado podrá parecer a algunos intolerablemente cínico, pero el objetivo de Maquiavelo no es justificar una conducta - que, por otra parte, reprueba- sino poner de relieve el carácter condicionante de las circunstancias. Una vez tomadas las armas no hay término medio entre seguir luchando en pos de la victoria o sufrir las consecuencias de la derrota; las posibilidades de la libertad de elección quedan circunscriptas por las exigencias de la necesidad inscripta en la lucha política. En esos extremos, “... los hombres prudentes saben siempre atribuirse el mérito de lo que la necesidad los obliga a hacer..." (Maquiavelo, Discursos: Libro I, cap. 51).

Es natural que Maquiavelo, para quien los hombres están no sólo animados por deseos y pasiones inextinguibles sino también más inclinados al mal que al bien, conciba a la comunidad política como una realidad esencialmente conflictiva en donde los odios y ambiciones amenazan constantemente estallar en violencia. El conflicto es visto como una realidad positiva en tanto que es el motor que mantiene en vida a la libertad ${ }^{14}$. Pero para cumplir esa función las pasiones humanas que alimentan el conflicto deben encontrar un cauce normal que evite la violencia. Refiriéndose a la importancia que para el mantenimiento de la libertad en una república tienen las instituciones que permiten acusar a los ciudadanos ambiciosos ante el pueblo, dice Maquiavelo que tienen la ventaja de “... ofrecer una salida normal a los humores que, por una razón u otra, fermentan en las ciudades 
contra tal o cual. Si estos humores no encuentran una salida normal, recurren a los medios extraordinarios, ruina de las repúblicas. Nada, por el contrario, hará firme y segura a una república como canalizar, por así decir, por la ley, los humores que la agitan..." (Libro Discursos: I, cap. 7). Aparece aquí con bastante claridad cuál es el papel que se le asigna a la razón en la construcción de un orden político. Ese papel no es el de extinguir las pasiones en los hombres -tarea por otra parte imposible- sino "... tomar las medidas más apropiadas para poner un freno a las pasiones de los hombres..." (Maquiavelo, Discursos: Libro I, cap. 42; El Príncipe: cap. 25) mediante la construcción de diques que canalicen a las mismas a fin de que no estalle la violencia. Esos diques son las leyes, obras de la razón. Pero los que las redactan deben partir del supuesto de que los hombres no son razonables. Para Maquiavelo fundar o reformar un estado, es decir, darle a una comunidad política un adecuado ordenamiento legal, es el mayor timbre de honor que pueda atribuírsele a un hombre público ${ }^{15}$. La razón no anula la pasión; sólo puede controlarla. Se comprende así su preferencia por la forma mixta de gobierno, ya que ésta, al incorporar a los grupos portadores de pasiones encontradas, crea las condiciones para su mutua neutralización ${ }^{16}$.

El modelo de sociedad política que propugna Maquiavelo no está fundado en el mutuo consentimiento y no está organizado en función de la cooperación razonable entre los ciudadanos. Está fundado, por el contrario, en el antagonismo mutuo y está organizado con miras a la institucionalización del conflicto, el cual es reconocido como una realidad permanente y, dentro de ciertos límites, necesaria para la vigencia de la libertad. El pesimismo antropológico le permite descartar las soluciones ilusorias, pero no desemboca en el pesimismo político, aun cuando tenga que reconocer la fragilidad que en este orden tienen las realizaciones humanas.

$$
\text { * * * }
$$

Para concluir, quisiera reflexionar brevemente acerca de algunas cuestiones que han surgido a lo largo de la exposición y que, a mi entender, están conectadas con la crisis que atraviesa la ciencia política contemporánea.

El lector de los innumerables libros y revistas que se publican en el mundo dedicados a lo que genéricamente se denomina "ciencia política" no sólo toma contacto con una serie de conclusiones intelectuales obtenidas luego de laboriosas investigaciones, sino que a través de ellos es hecho partícipe de las preocupaciones e intereses que animan a una comunidad profesional de científicos. La pregunta que cada vez con más insistencia formulan algunos de éstos respecto a la relevancia que tienen dichas conclusiones nos demuestra que por esta vía se está replanteando el viejo problema del fin que persigue la reflexión política.

El pensador profesional que hace de la investigación su medio de vida está ante todo preocupado por obtener la aprobación de sus colegas, y esa aprobación 
se obtiene adoptando los procedimientos y desarrollando los temas aceptados por los mismos; con lo cual el científico político profesional termina escribiendo e investigando cosas que interesan principalmente, o exclusivamente, a los miembros de su comunidad profesional. Hay muchas razones de orden sociológico que explican este comportamiento, pero la consecuencia del mismo es que se pierde de vista la finalidad principal del conocimiento político: operar sobre la realidad.

No debe verse en esta afirmación la adhesión a una concepción de la ciencia que tienda a favorecer las investigaciones aplicadas o los trabajos de "ingeniería social" en desmedro de las reflexiones puramente teóricas. Un remiendo de este tipo dejaría intactas, en efecto, las condiciones de vida y de trabajo de la comunidad científica en gran parte responsable de su esterilidad intelectual. Lo que está en cuestión, creo, es la posibilidad de aprehender una realidad como la política, para operar sobre ella desde la perspectiva del espectador, sea éste neutral o no. El científico político puede emplear diversos métodos para comprender el significado que ciertas acciones tienen para determinados actores, pero nunca podrá reemplazar adecuadamente el conocimiento que obtiene el actor a través de su propia experiencia de la realidad política. No es casual que la inmensa mayoría de los grandes pensadores políticos, de Platón a Lenin, pasando por Maquiavelo y los autores del Federalista, hayan sido protagonistas de las luchas políticas de su época. Nos hablan de una realidad que conocieron por dentro como políticos, y que no meramente observaron a distancia como científicos.

$\mathrm{Si}$ es verdad que toda actividad despierta en el hombre las pasiones propias de la misma, y que la vivencia de dichas pasiones constituye una valiosa fuente de información para comprender el sentido de la conducta humana, resulta no sólo improcedente sino contraproducente segregar al científico político en una universidad dedicándolo con exclusividad a investigar una realidad de la que se le prohibe participar. Porque allí experimentará todas las pasiones propias de la vida universitaria, pero no las que suscita la actividad política. Para que la reflexión política sea fecunda tiene que ser realizada desde el corazón del fenómeno que se analiza, porque desde allí el actor adquiere un panorama que le permite percibir ciertos hechos que el espectador no advierte, y a través de su experiencia singular obtener una comprensión más cabal de los complejos factores que intervienen en la determinación de la conducta política ${ }^{17}$.

Quizás en ningún problema se vea mejor reflejada la necesidad de un cambio de perspectiva que en el de los valores. Gran parte de la discusión acerca del papel que juegan los valores en el método científico se comprende si se la inscribe en el marco del ideal que sitúa al investigador fuera de la realidad que investiga. Se reconocerá como inevitable que los valores propios se expresen de un modo u otro como preferencias subjetivas de éste, pero no se aceptará un discurso acerca de la verdad objetiva contenida en los diferentes sistemas morales. El científico describe conductas pero no debe inmiscuirse en los problemas de la ética política. 
Esta compartimentación de atribuciones -el científico estudia lo que es, el filósofo lo que debe ser- introduce una discontinuidad en el objeto estudiado que éste no tolera. Porque si bien distinguir adecuadamente los diversos planos de la reflexión contribuye a obtener un conocimiento más riguroso, establecer entre los mismos barreras infranqueables es desconocer que entran continuamente en diálogo en el hombre en acción. Este no se entretiene en especular acerca de las ventajas relativas de un conjunto abstracto de proposiciones independientemente de su contenido ético. Colocado en una situación concreta tiene que tomar decisiones donde no sólo se hallan involucrados aspectos técnicos sino también convicciones éticas. El espectador puede eludir los problemas éticos, o formular juicios en abstracto; el actor está obligado a optar por uno u otro camino. Lo que Maquiavelo expresa a través del principio del mal menor es una experiencia que padecen duramente muchos intelectuales cuando son llamados a ocupar roles políticos.

En la presente crisis se halla en juego el fundamento antropológico que se le quiera dar a la ciencia política. Hacer ciencia sin efectuar previamente una reflexión crítica acerca del hombre conduce a trabajar, sin saberlo, con un "homo politicus" caracterizado por determinadas teorías filosóficas. Sería difícil negar que tanto la vertiente rousseauniana como la marxista tienen una visión optimista del hombre y de su progreso a través de la historia, y que ese optimismo racionalista subyace a muchos análisis contemporáneos. Maquiavelo nos llama en cambio la atención acerca de la finitud del hombre y de la presencia irreductible del mal en el mundo. Este debate acerca de la naturaleza del hombre, que tiene hondas implicancias en la práctica científica, debe dilucidarse apelando a una experiencia más amplia que la meramente intelectual. Exige, a mi juicio, que el hombre tome conciencia de la multidimensionalidad de su ser; que reconozca que es al mismo tiempo sujeto de razón y de pasión, que desarrolla actividades teóricas y prácticas, que su existencia tiene una dimensión privada y otra pública, que su conducta está determinada por imperativos lógicos y éticos. Para ello deben desaparecer las barreras que compartimentan su existencia impidiéndole tener una experiencia global de la vida que le revele la riqueza de su propia naturaleza. Pienso que una reflexión política, para ser fecunda, debe asentarse sobre una experiencia semejante porque en último término la política es una acción de y para los hombres. 
Fortuna y virtud en la república democrática

\section{Bibliografía}

Anglo, S. 1971 Machiavelli (Londres) pp. 215-243.

Aristóteles 1983 Etica a Nicómaco (México, UNAM). Libro I, 1095²-4.

Aristóteles 1951 Política (Madrid: Instituto de Estudios Políticos) Libro III, cap. $2,1275 b 34-1276^{\mathrm{a}} 6$.

Bonadeo, A. 1969 "The role of the 'Grandi' in the Political World of Machiavelli”, en Studies in the Renaissance Vol. XVI, pp. 9-30.

Cadoni, G. 1962 “Libertá, reppublica e governo misto in Machiavelli”, en $R i$ vista internazionale di filosofia del diritto Vol. XXIX, serie 3, pp. 462-84.

Colish, M. J. 1971 “The Idea of Liberty in Machiavelli”, en Journal of the History of Ideas Vol. XXXII, N ${ }^{\mathrm{o}}$ 3, pp. 323-350.

Chabod, F. 1965 Machiavelli and the Renaissance (Nueva York) pp. 126-148.

Gilbert, F. 1965 Machiavelli and Guicciardini: Politics and History in Six teenth-Century Florence (Princeton) pp. 152-170.

Gray, Hanna H. 1967 "Machiavelli: the Art of Polities and the Paradox of Power”, en Krieger L. y F. Stern (editores) The Responsability of Power: His torical Essays in Honor of Hajo Holborn (Garden City) pp. 34-53.

Janet, P. 1948 Historia de la ciencia política (México) p. 546.

Maquiavelo, Nicolás 1978 Historia de Florencia (Madrid: Alfaguara).

Maquiavelo, N. 1987 Discurso sobre la primera década de Tito Livio (Madrid, Alianza).

Maquiavelo, N. 1981 El Príncipe (Madrid, Alianza).

Mesnard, P. 1951 L'essor de la philosophie politique au XVI siècle (París) p. 83.

Namer, E. 1961 Machiavel (París) pp. 87-96.

Renaudet, A. 1956 Machiavel (París) pp. 119-152.

Whitfield, J. H. 1955 “On Machiavelli's use of Ordini”, en Italian Studies (ciudad) Vol. X, pp. 19-39. 
Notas

Agradezco a Carlos Floria, Natalio Botana y Ezequiel de Olaso las observaciones efectuadas a una versión previa a este trabajo. Publicado en Desarro llo económico, $\mathrm{N}^{\circ}$ 49, vol. 13, abril-junio 1973.

1 “... La cosa es más difícil cuando se trata de los que participaron de la ciudadanía a causa de una revolución. (...) Pero lo que se discute en este caso no es quién es ciudadano, sino si lo es con justicia o sin ella. También podría uno preguntarse si en el caso de que alguien sea ciudadano injustamente, no dejará también por eso de ser ciudadano, puesto que injusto equivale a falso. Pero puesto que vemos que algunos gobiernan injustamente y decimos que gobiernan, aunque no con justicia, y hemos definido al ciudadano por cierto ejercicio del poder (...) es evidente que debemos llamarlos ciudadanos..." (Aristóteles, 1951: Libro III, cap. 2, 1275b34-12766).

2 "... He expresado en esta obra todo lo que sé y todo lo que he podido aprender de las cosas del mundo a través de una larga práctica y una lectura asidua..." (Maquiavelo, Discurso sobre la primera década de Tito Livio: Dedicatoria). Sobre el problema del método en Maquiavelo pueden consultarse las siguientes obras: Renaudet (1956: pp. 119-152), Gilbert (1965: pp. 152-170), Chabod (1965: pp. 126-148), Namer (1961: pp. 87-96), Anglo (1971: pp. 215-243).

3 Que cita en el mismo sentido a Janet (1948: p. 546).

4 En este contexto general deben leerse afirmaciones como éstas, dispersas en la obra de Maquiavelo: “... Se puede decir una cosa en general de todos los hombres: que son ingratos, volubles, simuladores, enemigos del peligro, ávidos de las ganancias..." (El Príncipe: cap. 17).

5 Ver al respecto el interesante artículo de Gray (1967: pp. 34-53).

6 “.... Estos medios son crueles, sin duda, y contrarios no sólo a todo cristianismo sino a toda humanidad; todo hombre debe aborrecerlos, y preferir la condición de simple ciudadano a la de rey, al precio de perder a tantos hombres. Sin embargo a quien no quiere escoger el camino del bien, porque desea mantenerse en el poder, le conviene entrar en este mal. Pero la mayoría de los hombres escogen una vía media, que son las peores de todas; porque no saben ser ni totalmente buenos ni totalmente malos...". (Maquiavelo, Dis cursos: Libro I, cap. 26). “... Los hombres no saben ser ni honorablemente malos ni perfectamente buenos, y cuando una mala acción presenta alguna grandeza o magnanimidad, no la saben cometer...". (Maquiavelo, Discursos: Libro I, cap. 27).

7 La crítica que Maquiavelo hace a la manera en que se interpreta al cristianismo en su época se funda en que destruye las virtudes propias del ciudadano (Discursos: Libro II, cap. 2). 
8 “... Es el bien general y no el interés particular lo que hace poderoso a un estado; y sin discusión sólo en las repúblicas se tiene en vista el bien público. (...) Lo contrario ocurre bajo el gobierno de un príncipe: casi siempre su interés particular está en oposición con el del estado...” (Maquiavelo, Discursos: Libro II, cap. 2).

9 “... Un príncipe prudente no puede ni debe cumplir su palabra cuando tal observancia le sea desfavorable y ya no existan las circunstancias que le obligaron a empeñarla. Si los hombres fueran todos hombres de bien, mi precepto no sería bueno; pero como son malvados y ellos tampoco la respetarían, tú tampoco debes respetarla..." (Maquiavelo, El Príncipe: cap. 18).

10 “... Pues tal es la suerte de las cosas humanas que no se puede evitar un inconveniente sin caer en otro. (...) Hay que elegir, pues, en todas nuestras resoluciones el partido que tenga menos inconvenientes; pues no hay ninguno que esté totalmente exento...” (Maquiavelo, Discursos: Libro I, cap. 6). “... Pero (el Senado) juzgó las cosas como hay que juzgarlas, y tomó siempre el partido del mal menor como el mejor..." (Maquiavelo, Discursos: Libro I, cap. 38).

11 “... Soy de la opinión de que es mejor ser impetuoso que respetuoso, porque la fortuna es mujer y es necesario castigarla para mantenerla sumisa. Y se ve comúnmente que ella se deja vencer más bien por aquéllos, que por los que proceden fríamente. Por eso, como mujer, siempre es amiga de los jóvenes, porque tienen menos respeto y más ferocidad, y la mandan con más audacia..." (Maquiavelo, El Príncipe: cap. 25).

12 “... Repito, pues, como una verdad irrefutable y cuyas pruebas están en toda la historia, que los hombres pueden secundar a la fortuna pero no oponérsele; tejer los hilos de su trama y no cortarlos. No deben nunca abandonarse. Ignoran cuál es su fin; y cómo la fortuna no obra sino por vías oscuras y sinuosas, les queda siempre la esperanza; y de esta esperanza deben extraer la fuerza de nunca abandonarse, cualesquiera sea la miseria o el infortunio en que puedan encontrarse...” (Maquiavelo, Discursos: Libro II, cap. 29).

13 “... Las manos y la lengua de los hombres, esos dos nobles artesanos de su grandeza, no lo habrían nunca llevado a la perfección en que lo vemos sin el impulso de la necesidad..." (Maquiavelo, Discursos: Libro III, cap. 12).

14 “... En toda república hay dos partidos: el de los grandes y el del pueblo. Y todas las leyes favorables a la libertad nacen de su mutua oposición..." (Maquiavelo, Discursos: Libro I, cap. 4). Sobre la opinión de Maquiavelo respecto de los "grandes" ver Bonadeo (1969: pp. 9-30). Con respecto al concepto de libertad debe consultarse el exhaustivo trabajo de Colish (1971: pp. 323-350).

15 Sobre este punto ver el documentado artículo de Whitfield (1955: pp. 19-39).

16Se encontrará una buena discusión sobre el tema en Cadoni (1962: pp. 462-84). 
17 Sobre el rol de la experiencia en el conocimiento de la política, el juicio de Aristóteles es significativo: “... De allí que el hombre joven no es un oyente adecuado de las lecciones sobre política, pues carece de experiencia de las cosas de la vida, que son sin embargo el punto de partida y el objeto de los razonamientos de esta ciencia..." (Etica a Nicómaco: Libro I, 109522-4). 